\title{
Teaching Written Translation Online: Theoretical Model, Software Development, Interim Results
}

\author{
Alexey I. Gorozhanov ${ }^{1}$, Elena F. Kosichenko², and Innara A. Guseynova ${ }^{3}$ \\ ${ }^{1}$ Moscow State Linguistic University, E-Learning Centre, 119034 Ostozhenka 38, Moscow, Russian Federation \\ ${ }^{2}$ Moscow State Linguistic University, Department of General and Comparative Linguistics, 119034 Ostozhenka 38, Moscow, Russian \\ Federation \\ ${ }^{3}$ Moscow State Linguistic University, Vice Rector's Office, 119034 Ostozhenka 38, Moscow, Russian Federation
}

\begin{abstract}
Teaching translation online is based on the following principles: compliance with norms and rules of social interaction in the virtual environment; recognition of the fact that the tutor is an expert in the field of theory and practice of translation and a mediator between the student and the virtual environment; availability of a communication channel for regular interpersonal contact between the tutor and the student for expert consultation. The E-learning Centre at Moscow State Linguistic University was set up in 2016 with the aim of developing foreign language online programs and delivering related online courses, part of which are courses in written translation that have proved their effectiveness mostly due to the proper theoretical and methodological basis. The English-Russian translation course discussed in this paper aims to develop translation competence through practicing translation of original articles from BBC websites. After the student accomplishes the translation of one text, he meets the tutor at a video conference to discuss the mistakes and to contemplate the difficulties of the next text. The ability to explain the reasons of mistakes, to minimize the chance of their occurrence in future is the tutor's top priority that is based on his/her professional competence.
\end{abstract}

\section{Introduction}

The increasing popularity of online education in all fields of knowledge calls for more flexible approaches to higher education and new creative ideas in high school curricula. With modern information and communication technologies widely used in foreign language teaching, written translation remains mostly a face-to-face activity as it suggests direct knowledge transfer from the expert to the student. In this paper we are sharing the recent experience of an online written translation teaching course developed at Moscow State Linguistic University (MSLU). The paper gradually reveals that the practical value of this course arose from new philosophical ideas and a lot of theoretical analysis of the latest social tendencies.

\section{Theoretical Foundations}

The numerous discussions about the work of a translator that have recently been held not by specialists in the sphere of written or oral translation, but by people who have quite a vague idea of what the translator's work is actually about, abound with remarks that require a response from the professional community. The expert community of translators comprises specialists in oral and written translation and interpretation as well as those philologists, linguists and specialists in cross-cultural communication who have had at least three years' experience in translation. This factor seems important for a number of reasons. Firstly, there is a noticeable shortage of professional translators, which conditions their gender and age characteristics. In international organizations and different governmental and business structures, the average age of translators is approximately 60 years; most of the staff are male; however, the gender index can vary depending on the nature of texts for translation. The next generations of professionals, though sometimes highly qualified, often need more training and working experience.

Secondly, there are hardly any translation departments at most commercial enterprises, which means that the work is done by young specialists aged between 25 and 35 who are fluent in a foreign language but who often lack professional training, which affects the quality of both written and oral translation they do. This situation has been triggered by the recent general closure of faculties, institutions and universities that used to train translators - such institutions are often believed to be unnecessary as preparing professionals in this field is deemed extremely costly. There is no denying that training written and oral translators is far more expensive than inviting young specialists to enroll in an elective course at a university or even outside any higher educational institution where they acquire B2 level skills of English, which is the only choice at most institutions of this kind.

Thirdly, the devastating effect was caused by the well-known claim that there is no need for professional translators in the context of globalization as all people can use a lingua franca to communicate with each other. Today it is English that has by default been recognized as the means of intercultural communication despite the fact that due to the above-mentioned circumstances it is now a hybrid entity that has only a distant resemblance to Standard English (British variant). This is actually the reason why hybrid ironical words, like Denglish 
(German and English) or Chinese English (Chinese and English) appear. The decision against professional translation training, and - as a result - against professional translation competency has led to the emergence and spread of what A. Wierzbicka calls semantic primitives (Wierzbicka 1999), or what Saharnij calls primitive languages (Saharnij 1997: 139-140).

Fourthly, the categorical claims that oral and written translators are easily replaced by information technologies and computational solutions that exist in the digital environment, need explanation and wellgrounded scientific evidence.

It is worth noting that oral and written translations require that future interpreters should have different competencies. This is the reason why in Russia translation and interpretation is taught gradually - first students practice translating texts from foreign language into their native language, then from their native language into foreign language and finally students are trained to translate texts both ways and to do consecutive translation. Unlike in most educational institutions all across the world, the main approach to training translators in Russia consists in the special focus on general translation competencies at the first stage with the opportunity to specialize in a certain sphere at the second stage, in other words students first acquire common competences and later develop the most needed professional skill.

It is important to differentiate between different kinds of translation, like translation of technical, special, fictional and other types of texts. Another important point is to pay attention to the special nature of audio and visual translation, audio description (the Russian term is tiflocommentary), translation from the language of gestures into natural language, the other way round and both ways. Another thing to understand is that memory programs, e-dictionaries and data bases - that emerged as a result of a wide-scale usage in the practice of translation of methods of corpus linguistics and language recognition technologies (programs that serve to translate speech sounds into written texts) - are all instruments of support for the translator that help him organize and foster his/her work without causing damage to the quality of translation.

In the last fifty-sixty years there has been a lot of profound research in the field of machine translation that is now widely used and is bound to become still more widespread in the technical sphere whose terminological systems (for instance in the field of aircraft building) need systematization and unification. It is well-known that developing international quality standards requires common usage of separate terms. It all means that demand for information technologies in translation will grow noticeably; it also means that at the background of the so popular idea of multicultural and multilingual communication the significance of glossaries of terms should not be overlooked.

The conveyed ideas trigger the logical question about the very possibility of training and retraining highlyqualified interpreters of today and tomorrow with regard to the existing extralinguistic factors. Thus, we are putting forward the bold idea that the problem can be solved by devising schemes of applied character that open way to digital space and simultaneously preserve the role and the significance of the human factor. We are convinced that it is high time principles of interaction between human and technical information sources should be studied and described, and a conceptual foundation of the dialogue between man and the computer should be set up. It means that in the digital economic context of today any kind of computer teaching program is essential for training professional interpreters. It seems beneficial to adhere to the principle of complementarity suggested by Niels Bohr (18851962), whose aim was to reconcile the traditional system of knowledge with the progressive ideas and standpoints that emerged in the course of scientific cognition (Rosenfeld 1967: 85-86). It is highly important to stress that it is the principle of complementarity that lays the basis for "cooperation and partnership" (Guseynova 2009: 217). We suggest the following basic rules that secure the implementation of the principle of complementarity:

in the course of training and retraining translators, it is crucial to adhere to norms and regulations that exist in the virtual environment; in order to avoid pragmatic failures that can be destructive for the actual professional work of trainee translators, these rules may never be broken;

during social and cultural interaction both the teacher and the learner rely on the presumption that the teacher is an expert in the field of theoretical and practical translation;

in the course of studies the teacher performs the function of a mediator, who structures and supports the dialogue between the learner and the virtual environment;

implementing a training program both the teacher and the learner have the possibility of regular interpersonal contact, so that the learner could obtain an expert opinion.

We will now show how the conveyed theoretical and methodological principles are used to create a teaching virtual environment with regard to the specific nature of training and retraining highly qualified specialists in the field of translation.

\section{Technological Basis}

The technological basis for teaching and learning foreign languages online is for the most part learning management systems (LSMs) that have been actively developed since the 1960s (Levy 1997: 15-19). The LMS Moodle 3.0+ is deployed at the E-Learning Centre of MSLU. This system has proved to be a proper tool both for teaching and learning online (Conijn 2017; Fernandes 2013; Gomez-Aguilar 2011; Jackson 2017; Nash 2016). By adding "+" to the version designation we mean that the standard core of the LMS Moodle 3.0 installation has been modified to be a more effective tool for teaching foreign languages.

The modifications of the standard installation of the LMS Moodle 3.0 concern the following: 
adjustments in the roles hierarchy subsystem;

installation of additional plug-ins ("Adaptable theme", "Adaptive quiz", "Online audio recording", "Ordering", "Cloze editor", "Word count", "Buttons format", "Freehand drawing", "Preg question type" and "Virtual keyboard");

improvements in translation of the English interface labels into Russian;

- a number of changes in the programming core of the system.

The latter modification is closely related to the specific methodological nature of foreign language learning and teaching. This part has notably been improved due to the changes in the programming code of the LMS Moodle "Assignment" module, which initially supports limitation on the maximum number of words only, while for our, so-called, open tasks a limitation on the minimum number of words needs to be provided. In the latest version of the "Assignment" module the teacher can limit the minimum number of words in an open task, and the maximum number of words will be automatically calculated by the formula "minimum limit +300 words".

Another important programming block that was added to the server side code of our system was an interactive vocabulary trainer. The "trainer" outputs randomly 10 units of the course vocabulary. By clicking on any unit the student causes a pop-up window containing a description of the selected unit to appear. The "trainer" can be created from the standard LMS Moodle "Glossary" module thanks to the special software developed in the Python programming language.

For security reasons and due to the fact that the system is commercial, new users can be added to the LMS Moodle by the system administrator only, though the demo versions of the courses are available without registration but by using limited guest access.

Finally, the modified LMS Moodle provides a desktop/tablet/mobile interface depending on the user's device that is detected automatically.

\section{Theoretical Model}

All online courses at the MSLU E-Learning Centre are developed in line with the theory of the Institutional Virtual Learning Environment (IVLE) that is defined as "populated" organized and self-organizing (synergetic) dynamic professional institutional information space, which serves the purpose of incrementing positive knowledge, and also performs a number of particular tasks, consists of connected nodes which are deployed in the Internet and are accessible through authorized user accounts with roles hierarchy. It provides for its further development and, for improving its quality with increasing experience gained in it in the form of feedback, remains an individualized tool for gaining experience during study (work) in the given organization.

The IVLE can have specialization, depending on the tasks it performs. One of the most important modifications of the IVLE is a commercial IVLE $(\operatorname{IVLE}(\mathrm{c}))$. The learning process inside the $\operatorname{IVLE}(\mathrm{c})$ is based on the following principles:

learning is individual;

the blended learning technology is used;

the process of self-study is guided;

the course has a considerable number of open tasks;

the learning process is highly dynamic;

all learning materials are concentrated inside the node (course).

These principles lay the basis for structural models of online courses that can be realized in the form of special courses that perform a range of tasks assigned to them.

Each model describes a system of individual components - structural modules, which all together form a course and can be represented by programming modules of the LMS Moodle. A number of structural modules can be combined into a block.

The model of the professional course, which is basic for the written translation course, contains the following structural modules:

theoretical structural module (TSM);

vocabulary structural module (VSM);

open task structural module (OSM);

manual structural module (MSM);

file structural module (FSM).

The structural modules are grouped within the blocks (lessons) and are ordered through the dependences subsystem, defining the learning curve within the course (see Fig. 1 and Fig. 2):

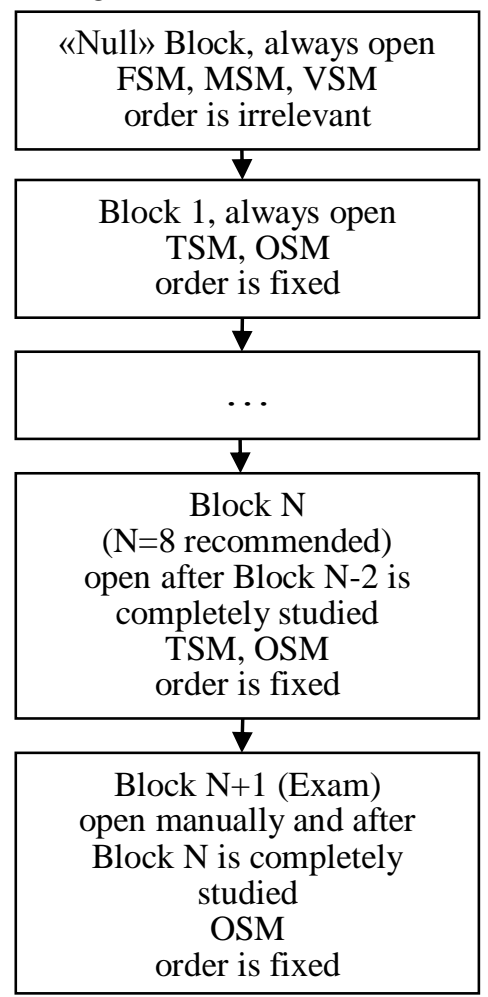

Fig. 1. Model of the professional course. 


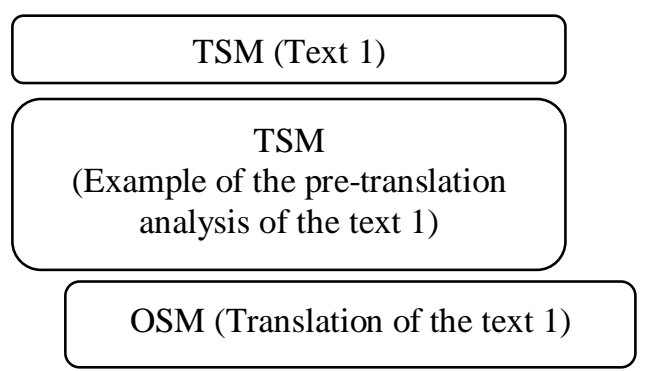

Fig. 2. Model of Block 1 of the professional course.

The dependences subsystem mechanism is based on the B. F. Skinner's "linear program" that complies with the principles of the guided self-study (Skinner 1968; Stern 1983: 306-307).

\section{Implementation and Results}

The described theoretical and technological principles lay the basis for two online courses for written translation from English into Russian - the course of the first stage and the course of the second stage. Both courses are parts of one written translation curriculum.

The course of the first stage is called "Written Translation of Mass Media Texts (English, High Level). Stage 1. Language, Education, Art" (Kosichenko 2016).

Accomplishing the course suggests that the student successfully copes with translating eight English media texts. By offering translations from English into Russian, the course secures the acquisition of basic translation competence.

The first block of eight is the largest and contains an example of the so-called pre-translation analysis of the text. Following the guides, the student deepens into the text structure and realizes the major difficulties translation implies. Paragraph-by-paragraph analysis of the English text is accompanied by appropriate Russian equivalents.

The first block is followed by the LMS Moodle module "Assignment" which requires that the student should submit the translation (optionally the text can be copied from any other text processor and be pasted into the module's text area). The module settings are designed so that the teacher's comment is embedded into the student's text. Mistakes are marked according to the rules for using background colours: red background wrong translation; yellow background - inaccurate translation; blue background - stylistic inaccuracy.

After examining the student's translation, the teacher may find it necessary to send the text for corrections, in which case the student will be given another attempt to submit the paper. If the translation is acceptable, the teacher blocks the assignment and after that the translation cannot be changed by the student. It is assumed that the final discussion of the completed text and the preliminary discussion of the next open task take place simultaneously during a videoconference.

To maintain the correct sequence of the self-study, the dependences subsystem is used in the following way:
Block 1 is open from the very beginning.

Block 2 is open from the very beginning.

Block 3 is open after Block 1 is completely studied. Block 4 is open after Block 2 is completely studied. Block 5 is open after Block 3 is completely studied. Block 6 is open after Block 4 is completely studied. Block 7 is open after Block 5 is completely studied. Block 8 is open after Block 6 is completely studied. The course of the second stage has similar structure.

\section{Teaching Principles and Practical Solutions}

Although it is clear from the previous part that the student works independently aiming to succeed in accomplishing the task so that the tutor would find his/her work acceptable, it seems highly important to stress that marking the student's paper and pointing out the mistakes made is by no means the tutor's main objective. The far more important stage is the preliminary discussion and the final discussion during a video conference, that is, cooperative work that secures good results of the student's independent effort. Besides explaining why this or that sentence or word in the submitted work seems to be a poor equivalent of the original lexical item or grammatical structure, the tutor's task is to come up with a couple of variants so that the learner could clearly see why his/her translation is being criticized. It should be emphasized that in addition to practical skills the course develops, its general idea is to convey to the learner the simple fact that there is no single "perfect" translation. This approach is beneficial in at least two ways. Firstly, it helps to avoid the harmful authoritarian approach in education and in science, which presupposes a so-called paragon, in this case an ideal translation. Secondly, the more variants are discussed during the video conference, the better idea of how to handle words and make the best use of syntactic constructions the student gets. In this way, teaching written translation sets high requirements to the teacher who is:

to command a large vocabulary in both the source and the target languages;

to be aware of the stylistic differences between synonymous words, grammatical forms and syntactic structures;

to have sufficient background knowledge so that to recognize allusions and make proper use of the social and cultural information they encode and transmit;

to possess the professional ability to explain the smallest differences in style and meaning that seemingly equivalent words and structures acquire in a certain context.

The teaching course that we are discussing contains original articles from BBC websites dealing with the various issues of human interest, like language, education, art, new technologies, economy and ecological issues. Though students occasionally complain about this or that topic or the author's style, they generally appreciate the selected materials. 
Although the course provides written recommendations for the learner on how to arrange work, the first video conference is partly devoted to the discussion of the most effective methods and approaches to dealing with texts. It is advised that students should not get down to translation before they do the pretranslation, that is, before they read the whole text, make sure they recognize the allusions it contains and can generally cope with the informative side of the text. It may also be beneficial to translate the segments that seem the most important. Once this part of work is accomplished, it is time to decide on how to handle the emotional aspect of the text, deal with the implications it contains.

Thus, one of the major problems each translator faces is allusions. Some illusions are easily recognizable, like these three names: Toni Morrison, Jeffrey Eugenides and Virginia Woolf that are associated with the most popular authors of bestsellers. Other allusions, like TEDx talk or Virago Modern Classic may take a bit of investigation; besides they pose a real problem as the translator is to decide on how to convey the encoded information to the reader, for instance, by making a reference or by introducing an explanation in the text. Among the whole range of challenges each original text poses its humorous implications seem the toughest, and that is the point all professional translators are unanimous about.

Another element of any text that takes a lot of consideration is its title. It is common knowledge that the title is a significant element of the text as its major purpose is to attract attention and inform the reader about the problem raised in the text. With this in view, it is highly recommendable to translate the text first and contemplate the title afterwards, bearing in mind that not a shade of meaning can be overlooked. However important it is to stick to both the original meaning and the original style, it is even more important to avoid (unless absolutely necessary) word-for-word translation or reproducing the original syntactic structure of the title.

Let us consider the title Children's Social Problems Cost $\$ 17$ bn a Year. The idea implied in the title is that social problems concerning children are quite costly. However, in the course of work we had to deal with a situation when a student decided to follow the structural arrangement of the title, which lead to a change in meaning. Instead of informing the reader about problems that children face, the translation conveyed the idea of small, insignificant problems. Russian grammar requires the usage of a genitive construction to convey the idea of who actually faces a problem.

Another example of an unsuccessful word-for-word translation is the one suggested by a student who decided in favour of the international word mobile while translating into Russian the title The Future of Education in Africa is Mobile. As the meaning 'relating to mobile phones' typical of the English language has not yet entered Russian, the idea ultimately conveyed is that the future of education in Africa is "able to move easily, or move a lot".

Another tip is to consult dictionaries of synonyms, especially dealing with polysemantic words as they may often be misleading. Let us consider the title The Secret
Code of Writing a Bestseller and the translation offered by a student whose native language is Russian and whose level of English is proficient due to many years of residence in the UK.

The English word secret that is crucial for the whole title has the meaning of deliberately not told to other people or kept hidden from other people (Macmillan English Dictionary for Advanced Learners). By using this word, the author of the article intends to convey information that is generally hidden from the public. One of the synonymous words of secret is mysterious, defined as: 1. not explained or understood; 2. not recognized or known; 3. keeping things secret (Macmillan English Dictionary for Advanced Learners bold type - ours). Thus, it must have been the third meaning that misled the student, who used the Russian word tainij (the closest English equivalent is mysterious). The student later explained that she had chosen the word tainij as she was willing to avoid the word-for-word translation and was generally reluctant to use an international root that the word secret displays. However, the Russian word sekretnij would definitely have been a better choice.

It was for the same reason that the student refrained from using the Russian word bilingv to stand for the English word bilingual when translating the article The Amazing Benefits of Being Bilingual. There is a Russian word dvujazichnij which is a loan translation of the word bilingual and which was the student's only choice. However, the Russian word bilingv is also widely used in Russian and employing it from time to time would have been a good idea as it would have spared the student the necessity to repeat the same word dvujazichnij up to 20 times. Thus, strange as it might seem, students sometimes go to the other extreme and refrain from using words of Latin origin (international words) altogether, which should be taken into account.

However, the most common mistake is still the inability of learners to find a proper equivalent of a foreign word or a phrase, or a structure while translating a text into the native language. Being deeply concerned with the meanings foreign words, grammatical forms and syntactical structures convey, the learner seems to forget that these meanings are to be properly verbalized in the target (native) language, which raises the problem of training future translators to deal with their native language as well. Thus, the ability to foresee possible mistakes and to minimize the chance of their occurrence is the tutor's top priority, as letting the student first make a mistake and then correct it might possibly be educational, but would hardly promote a positive outlook on the hard job of being a translator.

\section{Conclusion}

A brief investigation into the reasons why translation is losing its former professional status and whether it is beneficial to train specialists in oral and written translation despite the expenses and the general opinion that highly qualified specialists in this sphere can easily be replaced by people whose command of a foreign 
language (usually English) is graded as B2 shows that it is too soon to decide against professional training. The experience of MSLU that has for decades had a large department of Translation and Interpretation and has recently set up an E-learning Centre, where new translation online programs are developed and online courses in written translation are delivered, shows that professional training in this field is - in the final analysis - highly beneficial. The main argument for professional training is the popularity of the courses in question, as the work learners do - both while working independently or discussing things with the tutor during a video conference - not only fills the gaps in their knowledge but also provides a good opportunity to practice translation and get an expert opinion. Teaching translation is no less beneficial as it is a good way for the expert to upgrade his/her knowledge and to widen his/her own experience of practical work.

\section{References}

1. A. Wierzbicka, Semantic universals and description of languages, (Moscow, Yazyki Russkoy Kultury, 1999)

2. L. V. Saharnij, Text. Brain. Image of the World, 12th International Symposium on Psycholinguistics and Communication Theory (Moscow, RAN IYA, 1997)

3. L. Rosenfeld, Niels Bohr. Live and Work (Moscow, Nauka, 1967)

4. I. A. Guseynova, Genre organization of marketing discourse (Moscow, MSLU, 2009)

5. M. Levy. Computer-Assisted Language Learning: Context and Conceptualization (NY, Oxford University Press, 1997)

6. R. Conijn, Ch. Snijders, A. Kleingeld, U. Matzat, IEEE transactions on learning technologies, Los Alamitos, IEEE Computer Society 10(1), 17-39 (2017)

7. P. S. J. Fernandes, Moodle 2.5 Multimedia: Engaging Online Language-learning Activities Using the Moodle Platform (Birmingham, Packt Publishing, 2013)

8. D. Gomez-Aguilar, M. Conde-Gonzalez, R. Theron, F. Garcia-Peñalvo, Human-Computer Interaction, Springer 4, 604-607 (2011)

9. E. A. Jackson, Education and Information Technologies, Springer US 22(1), 177-193 (2017)

10. S. S. Nash, Moodle 3.x Teaching Techniques Third Edition (Birmingham, Packt Publishing, 2016)

11. B. F. Skinner, Reflections on a decade of teaching machines, Instructional process and media innovation (Chicago, Rand McNally \& Co., 1968)

12. H. H. Stern, Fundamental Concepts of Language Teaching, Oxford, Oxford University Press, 582 (1983)

13. E. F. Kosichenko, A. I. Gorozhanov, Science and Education» 10(89), 26-27 (2016) 